\title{
The Role of Social Participation for Women's Ability to Combine Motherhood and Employment Security in Mali and Ghana
}

\author{
Nadia von Jacobi \\ IUSS Pavia (LabExpo) and Università degli Studi di Pavia \\ nadia.vonjacobi@unipv.it
}

\section{Abstract}

This study investigates the role of social participation for the achievements of women in employment security and their fertility choices. In Capability terms, this implies exploring the circumstances in which women combine motherhood and employment security. Employment security is defined as having access to a job with more desirable characteristics, such as stable payment or in a more formal sector of the economy. The DHS and Afrobarometer data are used for two African countries: Ghana and Mali. Estimations from a multilevel model suggest that the resources of the context are a relevant explanatory factor for female employment security. The latent contextual effect for employment security is more pronounced in Mali (33\%) than in Ghana (I 7\%). Results confirm that the two countries are very different despite certain common effects. In both countries, social participation seems to play a role in the fertility-labour link, especially for women with more than four children.

Keywords: Mali, Ghana, employment security, conversion factor, context, social participation.

\section{Résumé}

\section{Rôle de la participation sociale dans la capacité des femmes à combiner maternité et sécurité d'emploi au Mali et au Ghana}

Cette étude analyse le rôle de la participation sociale des femmes pour leur sécurité d'emploi et leurs choix féconds. En termes de Capabilités cela implique d'explorer les circonstances qui permettent aux femmes de concilier la maternité et un emploi sûre. La sécurité d'emploi est définie par l'accès à un revenu stable ou une activité dans un secteur formel de l'économie. Les données des EDS et de l'Afrobaromètre sont utilisées pour deux pays, le Ghana et le Mali. L'analyse multiniveau montre que les ressources du contexte constituent un facteur explicatif pertinent de la sécurité des emplois féminins. Les effets latents du contexte sont plus marqués au Mali (33\%) qu'au Ghana (I 7\%). Les résultats confirment que les deux pays sont très différents malgré quelques effets communs. Dans les deux pays, la participation sociale joue un rôle dans le lien entre la fécondité et l'activité professionnelle, particulièrement pour les femmes ayant plus de quatre enfants.

Mots-clés: Mali, Ghana, sécurité d'emploi, facteurs de conversion, contexte, participation sociale 


\section{Introduction}

How women combine motherhood with employment remains a relevant question for development, especially in those contexts in which current fertility levels are high, and where demographic transitions are under way. The link between fertility and employment of women has been extensively studied in microeconomics. Findings in the literature suggest that fertility choices and participation in the labour market are deeply intertwined, or endogenously determined. The economic and sociological literature, on the other hand, indicates that household decisions can be significantly influenced by social factors, such as peer pressure and prevailing social norms.

This study explores the complex and multilevel relations between fertility, employment security and social participation in two African countries. The focus is on women. The role of men appears only in the measures of social participation at the context-level. Fertility refers to the woman's number of living children. Employment security is interpreted as having access to a job with more desirable characteristics, such as stable payment or being within a more formal sector of the economy. Social participation denotes the degree to which men and women - living within the context participate actively in community life, be it through memberships in groups or sporadic civic engagement.

I investigate the role the intensity and type of social participation can play in reducing vulnerabilities of women in Ghana and Mali. Women are identified as more vulnerable when lacking employment security and when located in a context where the combination of employment security and fertility is difficult. In Capability terms, this implies exploring the contexts in which women are able to combine motherhood and employment security. Social participation is seen as a collective conversion factor that alters the baseline position of employment security for women, and as collective endowment for rearing children.

The paper starts with a discussion of the potential role of social participation for development and women in particular. It then presents the main results of an empirical analysis in Ghana and Mali. Micro-level data from the DHS (Demographic and Health Surveys) are complemented by contextual characteristics calculated using the Afrobarometer surveys.' A random coefficients model is used to explain variation in female vulnerability through individual and contextual characteristics. Social participation enters into the model as an aggregate measure of the context.

\section{Theoretical Framework: Social Participation as a Collective Conversion Factor}

Why Does Social Participation Matter for Human Development?

Social participation is often studied as a vehicle for emancipation, empowerment and social mobility. It is an element of sociability and a good life (see for example Cicognani et al. 2008). Lack of participation has therefore been interpreted as a dimension of vulnerability itself (see Dieng in this volume). From a more 'macro' perspective, patterns and intensity of social participation seem to be linked to other "collective" achievements such as more democratic political systems, more intense cooperation, greater rights enforcement and more inclusive institutions.

Participation in community life contributes to social cohesion in general, by fostering trust: entering relationships with others requires at least positive expectations and reliance (Esau, 2008). Common values and perspectives can also evolve more easily in an environment of encounter and exchange. Intuitively, participation also promotes common experience that promotes a common horizon in terms of expectations, beliefs and cognitive frames. Bess et. al (2002) refer to communities with greater social participation as being more 'healthy' because of an ability to exhibit an "extra-individual quality of emotional interconnectedness of individuals" (Cicognani et al. 2008:99).

A consolidated sense of community can also imply greater investment in public goods for which returns are equally distributed among the population. Being able to 'rely' on social 
contacts can be further interpreted as a resource, which provides I) access to opportunities (flow and transmission of information and knowledge) and 2) riskbuffering (reciprocal altruism as mechanism of risk-mitigation) (see Platt 2006). In this sense, the presence of consolidated social networks can be thought to affect employment security, as we can expect a greater availability of job opportunities where social exchange is more lively.

Research Question I Does social participation enhance the employment security of women?

\section{Does a Context of Social Participation Promote} Equality?

In theory, social participation might not automatically foster achievements for everybody. It might perpetuate or increase inequalities within a society or even trace new lines of exclusion where individuals are stuck in tight social bonds that inhibit their upward mobility or if networks are used to promote the exclusion of others (Portes 1998, Lin 2001 in Platt 2006). Bourdieu's (1997) interpretation of social capital underlines the "maintenance of networks for individual advantage and retention of privileged social position” (in Platt 2006:I). Similarly, in Putnam's view (1993), social ties can be bonding, implying within-community stability or bridging, when they are more connected to upward mobility per se. Trust, cohesion and participation might indeed be used to reproduce advantageous positions and overall inequality. Within systems in which structuring processes take place, advantageous positions might be realized on the costs of others, causing marginalization of those located in less advantageous positions at the start.

I therefore conceptualize social participation as a contextual characteristic that can potentially play a "differentiating" role. I draw on the Capability Approach and in particular on the notion of conversion factor (see the first paper of the present volume). The literature agrees that conversion factors can be conceived at different levels. So far they have been contemplated at the individual, social and environmental level. At the individual level, conversion factors are typically identified with "personal heterogeneities" (ChiapperoMartinetti and Salardi, 2008:6). At the contextual level, social factors (Sen 1985), environmental diversities, economic settings and social norms (Sen 1992 and 1999) have so far been considered (see a conceptualization of contextual conversion factors in von Jacobi 2014).

Research Question 2 Is social participation a collective conversion factor that affects inequalities?

Participation, Women and the Fertility-Labour Link

Social interactions are the vehicle through which social norms and informal institutions influence individual decision-making. By interacting with others, individuals are subject to informational cascades (Bikhchandani et al. 1992), develop interdependent preferences (Postlewaite 1998) and assume herding behaviour (Banerjee 1992; Manski 1993) which can significantly shift a person's believes and parameters of choice. Social interaction promotes imitation and, possibly, innovation: a new social behaviour is observed on a peer, perceived as optimal, and imitated in disrespect of previous norms or habits (Conlisk 1980 in Manski 1993).

The fertility-labour choice can be influenced by social interaction: first, the transmission of information - especially in terms of personal experiences or accessibility of contraceptive methods - seems to play an important role for fertility choices (Kandori 1992; Bongaarts and Cotts Watkins 1996). Second, the enforcement of social norms - which typically defend a conservative view on fertility (Bongaarts and Cotts Watkins 1996; Amin 1997; Munshi and Myaux 2006) - requires social interactions in order to be effective. Reputation and social status can only be maintained or lost within a group.

On the other hand, a more cohesive society might provide opportunities for 'sharing' the costs of child rearing. Social participation of women is further implicitly linked to their empowerment and emancipation. The triangle 
between participation, fertility and employment therefore implies endogeneous relations. The analysis presented hereafter will identify correlations but not mutual causality. Following Luke's (2004) statement that "higher levels typically influence lower levels in hierarchies", one can however infer that contextual variables can influence decision-making through their effect on reasons and resources (Longshore Smith and Seward 2009), e.g. through peerpressure, prevalent cognitive frames or help from others in child-rearing.

The fertility-labour link is considered in qualitative terms by distinguishing two typologies: a substitution effect or an income effect. Income-effects imply that higher fertility levels are positively correlated to wealth. This could mean that poorer women might not realize their family project because of restraints in resources. On the other hand, an income effect can be interpreted as advantageous for women, because it implies that being a mother of more children and having a secure job is more feasible, on the average. A substitution effect refers to situations in which employment security is not compatible with a large family. It may reflect the situation of more 'empowered' women who combine lower fertility with employment and careers. It might also indicate that women 'pay' for higher fertility in terms of employment security. The triangulation with social participation allows comparing how the fertility-labour link varies in different contexts of social participation.

Research Question 3 Does a context of greater social participation, and of greater female participation, provide more favourable conditions for combining employment security and motherhood?

\section{The role of the life context}

Each woman faces and interacts with an environment of given intensity of social participation as circumscribed by the context, i.e. "material and non material circumstances that shape people's opportunity sets, and (...) circumstances that influence the choices that people make" (Robeyns 2005:99; emphasis added). ${ }^{2}$ The context can provide more resources and increase opportunities of action. Yet, it can also restrain the agency of an individual by shaping its reasons, beliefs, emotionality, memory and desires (Bhaskar 1998; Sayer 2000 and Archer 2002 in Longshore Smith and Seward 2009:222).

Reasons play a role for the choice of a woman between being a mother or a worker. Reasons can be influenced by the context for example through social norms or average schooling or local history. The context can also provide resources, for example through social networks. In the empirical analysis, I first estimate the overall latent effect of the context in other words: how much variability in employment vulnerability can be accounted for by the context. In specifying the factors behind the latent effect, I try to detect whether social participation plays a role. Is it associated to greater employment security? And are there patterns between social participation and the prevalent choice of how to combine employment with motherhood?

What kind of national scenario did women in Mali and Ghana face in 2008? According to Afrobarometer data, people in Ghana and Mali tended to express optimistic views on their national economic condition: $80 \%$ in Ghana, men and women, across diverse employment statuses. In Mali, optimistic views were common among roughly $60 \%$ of the population. A greater share of people replied that they "don't know" (I5\% of men, 22\% of women). Male part-time workers were particularly optimistic, while full time working women seemed to be less satisfied (53\% expressing that the economic situation had worsened).

The gender gap in schooling was still prevalent in both countries. In Ghana, I5 percentage points less women obtained any formal schooling. In general, only I5\% of the population completed secondary schooling. Education in Mali was much lower: $61 \%$ of women (47\% of men) did not have any formal schooling, and only II\% of women (16\% of men) achieved more than incomplete primary schooling. Full time workers tended in general to be more educated.

In terms of participatory attitudes, about 22$25 \%$ of men and $37 \%$ of women reported not 
being interested in public affairs in both countries, without clear differences between rural and urban areas. In Mali, people that were members of a voluntary association or a community group were not automatically more interested in public affairs (especially women). Only official leaders were systematically more interested. In Ghana, involvement in community groups was more closely linked to interest in public affairs and being an official leader did not make a big difference in this sense. In Mali, interest in public affairs was more pronounced among those that believed that an ordinary person can do a great deal to solve local problems, but only among men (I8\%), and not among women (42\%). In Ghana, such an opinion did not seem to play a role.

\section{Data and Methods}

Data

The data used in the empirical analysis are hierarchical, meaning that a nested data structure has been built. At the individual micro-level, I use the Demographic and Health Surveys of Ghana (2008) and Mali (2006). I derive some contextual variables from these datasets. In order to characterize social participation I use two Afrobarometer datasets for Ghana (2008) and Mali (2008). Afrobarometer surveys are conducted and regularly repeated - with comparable questions - in many African countries. A standard set of questions is included into the survey, along with more country-specific demands. Issues covered are democracy and governance, economy, approval ratings of leaders and institutions, decentralization and local government, living conditions, perceptions of corruption, security, national and ethnic identity, media and election preferences (www.afrobarometer.org).

The two data sources have been matched at the meso - or the contextual - level. Although the sampling structures of the two data sets differ, they are both representative at the regional level. ${ }^{3}$ By matching the data set only at the aggregate - contextual - level, quality of the nested data has been guaranteed.

The life context is defined by the woman's de facto place of residence. Each region (ten in
Ghana, nine in Mali) is further split into rural (less than 5000 inhabitants) and urbanization levels, such as towns (5000-50000 inhabitants), cities (50000- I m inhabitants) or large cities and capital (more than I million inhabitants). The final analysis therefore was run on two nested data sets in which 2094 (5097) women of age 15-49 are living in 3 I (25) different contexts in Ghana (Mali).

\section{Methods}

A. Indicators for employment security and social participation

\section{Individual Achievements in Employment Security}

I construct a composite indicator for employment security, interpreted as a multidimensional concept (Figure I). From a capability perspective, the indicator measures the achievement: enjoying employment security. The indicator combines three sub-pillars, which measure, respectively,

a. participation in the labour market (indwork): having a job

b. stability of earnings (indstability): earning regularly

c. degree of job formality (indformal): more formal.

a) The participation in the labour market is defined by three alternative situations: the woman is currently working (full achievement), not currently working/unemployed but has worked in the previous year (intermediate achievement), or inactive/long-term unemployed if she is not working and has not worked in the previous year (minimal achievement). A drawback to this definition is that it is impossible, in the DHS, to distinguish between unemployed and inactive women. Inactivity may be a reasoned choice which cannot be considered as inferior to the reasoned choice to participate. In this study, I assume that having a job is always more desirable than not having one: working therefore has an intrinsic value that goes beyond the necessity to earn 
money. Employment has important implications for autonomy, empowerment and self-realization, beyond providing material advantages.

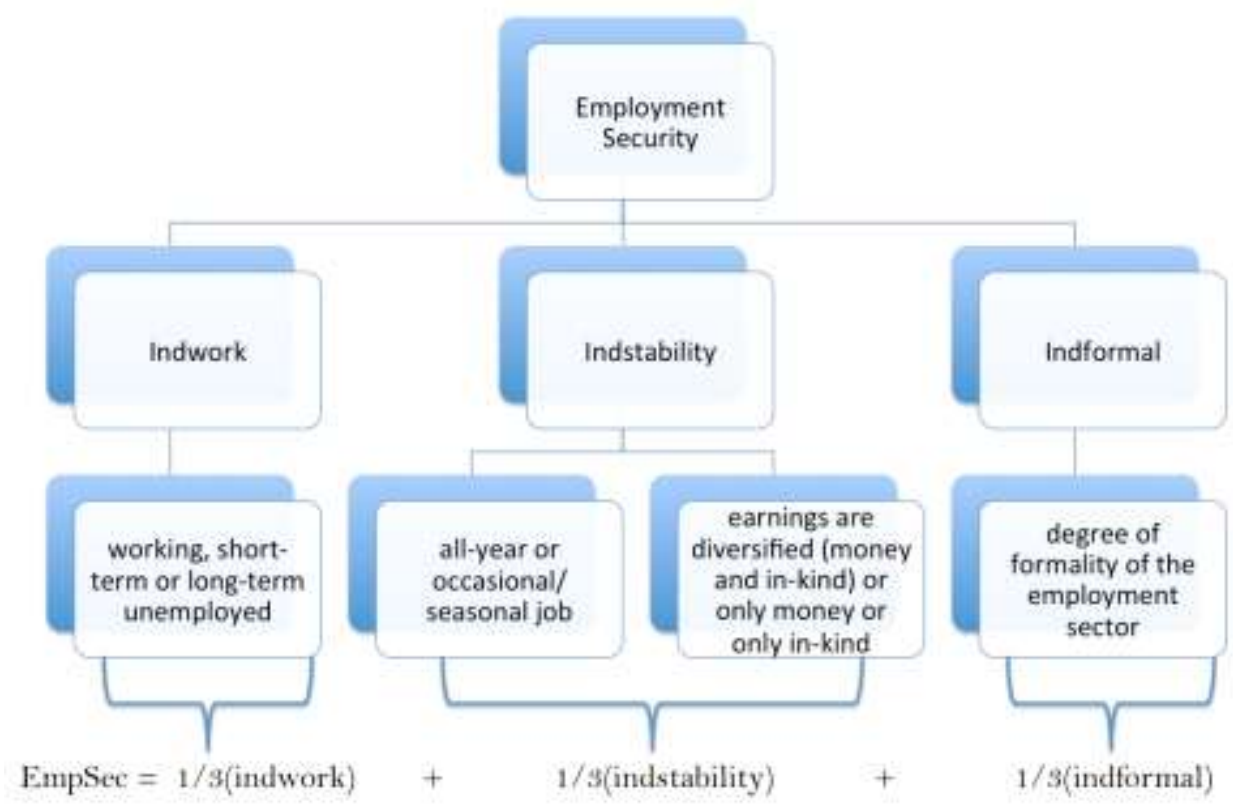

Figure I: Structure of the composite indicator of Employment Security. Source: author's elaboration using DHS data (2008 and 2006).

b) The second sub-pillar combines two variables that provide a measure of the stability of earnings: i) the annual rate of occupation (working the entire year, full achievement, or only in one season, occasionally or not at all) ii) the type of earnings along a "risk-diversification" axis, attributing the highest achievement to women who are paid both in cash and inkind, then being paid only in cash, only inkind, and not being paid. ${ }^{4}$ The subindicator Indstability is the arithmetic mean of both variables with equal weights.

c) The last sub-dimension records the degree of formality of the employment sector. Achievements (in descending order) have been attributed to formal jobs (e.g. public administration, clericals, managers or wholesalers in the trade sector), skilled manuals (e.g. tailors, beverage producers, weavers, carpenters), jobs in the service sector with high degree of substitutability (e.g. waitresses, cooks, bartenders, hairdressers), informal jobs (e.g. retail market traders, hawkers/street vendors). A distinction has been made to take in account that working conditions in the agricultural sector are difficult to compare to those of non-agricultural sectors, especially in terms of their degree of formality and, in agriculture, the role of land property. Thus women in the agricultural sector have equivalent achievements to a skilled manual in the non-agricultural sector when they work on their own land and to an informal worker when they don't work on their own land.

The employment security index aggregates the three dimensions represented in Figure I for women not working in the agricultural sector, while for agricultural workers $(23.6 \%$ in Mali, $19.8 \%$ in Ghana), it only combines the 
two indicators Indwork and Indstability. In line with composite indicator construction (Nardo et al. 2008), all variables and sub-indicators are normalized. It is assumed that the three (two) dimensions contribute equally to employment security although having a job clearly exercises a greater weight, in the sense that it is a necessary condition to enjoy employment security. I further choose a linear membership function, which implies that the reply options of the original variables can be considered as equidistant within a linear continuum of absolute deprivation and full achievement (ChiapperoMartinetti 1994, Chiappero-Martinetti and von Jacobi, 20II). The final index, which serves as dependent variable in the following analysis, is a quasi-continuous achievement indicator that ranges between 0 (no achievement) and I (full achievement).

\section{Social Participation Measured at the Context-Level}

Microdata from the Afrobarometer have been used to construct a comparable measure of the social participation context in both countries. As shown in figure 2, the indicator comprises two sub-pillars with a series of components:

- the intensity of membership in religious or community groups, which is in line with traditional measures of formal participation (e.g. Duffy 2004, Li et al 2002 and 2003, Warde et al 2003, Pennant 2005 all in Platt 2006:2)

- the participatory position, a hybrid measure of habit and attitude, measured as attendance to community meetings, joining others to raise an issue and attending a demonstration or a protest march. As the question addresses both, the frequency of participation and whether the person would participate if she/he had the chance, this sub-indicator grasps the attitude towards collective action and social participation potential even where this has not unfolded so

far.

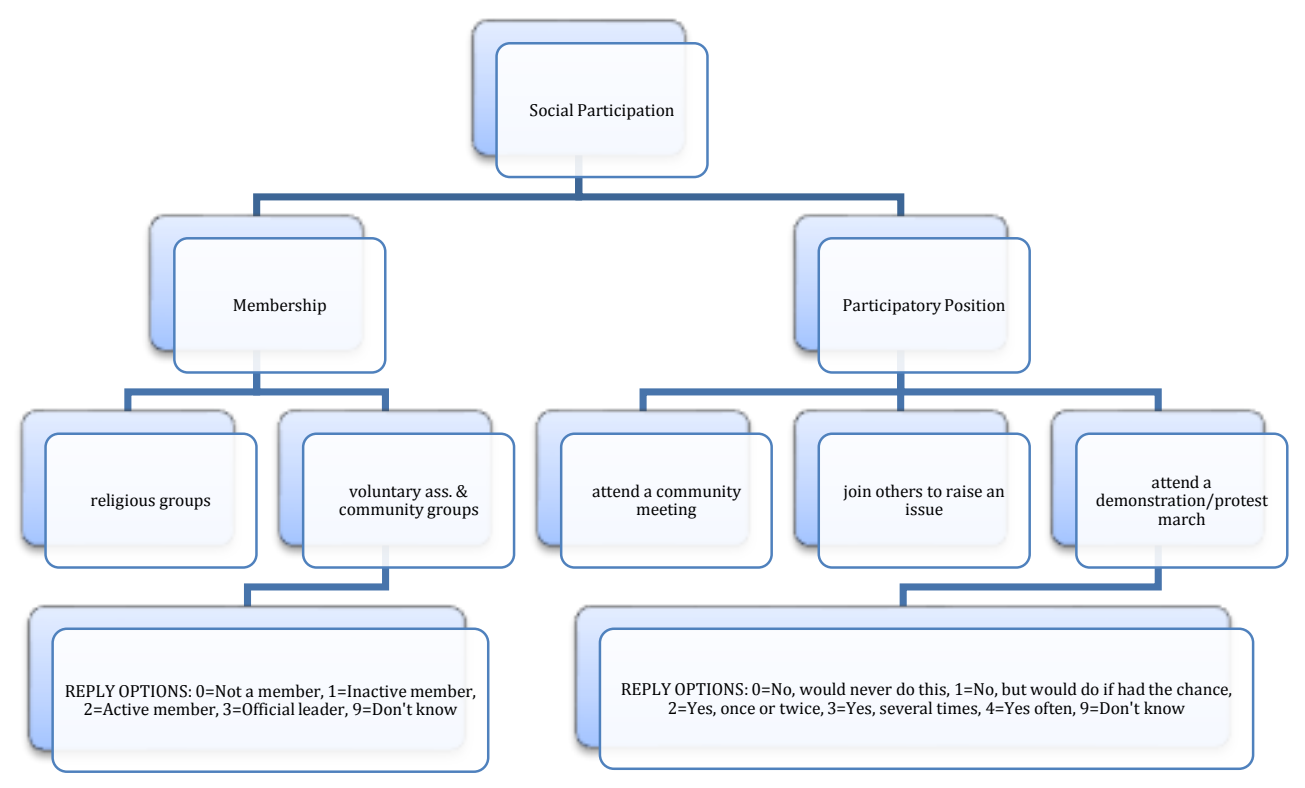

Figure 2: structure of the Social Participation composite indicator. Source: elaboration by the author using Afrobarometer data (2008) 
In the models used, we use both a global indicator combining the two sub-dimensions (Multilevel analysis, Table 2$)^{5}$ and specific measures of participation (Random slope analysis, Figure 5):

- The participation index (B) considers the percentage of individuals taking part in the activities listed here except demonstrations, which have a low frequency in both countries.

- The participation of women compared to men is measured through the ratio female/male in the (B) index, as well as in the

\section{- Membership index.}

An index of 'unsatisfied desire for more participation' records the share of people not participating who express the wish to be participating more.

\section{B. Empirical Strategy: a Multilevel Analysis}

In economic literature, random coefficients (multilevel) models are used to investigate unexplained variance at a superior level, in this case, the context. Their application allows the inclusion of contextual variables. Contextual variables, including social participation, are defined at level 2. Woman $i$ lives in the context j:

$$
Y_{i j}=\beta_{0 j}+\beta_{1 j} X_{i j}+\varepsilon_{i j}
$$

with $Y_{i j}$ measuring achievement in employment security, explained by average achievements in the context and individual characteristics, and the individual error term $\varepsilon_{i j} \sim N\left(0, \sigma^{2}\right)$. We expect women in the same context to be subject to a common effect: $\beta_{0 j}=\gamma_{00}+u_{0 j}$ and $\beta_{1 j}=\gamma_{10}+u_{1 j}$, where both context-level errors are $u_{0 j} u_{1 j} \sim N\left(0, \sigma^{2}\right)$ and orthogonal to $\varepsilon_{i j}$. Level-2 covariates explain the latent contextual effect. Any covariate defined at level 2 can change the context-specific parameters $\beta_{0 j}$ or $\beta_{1 j}$ :

$\beta_{0 j}=\gamma_{00}+\gamma_{01} W_{j}+u_{0 j}$ and $\beta_{1 j}=\gamma_{10}+\gamma_{11} W_{j}+u_{1 j} \gamma_{01} W_{j}$

The final multilevel model can be succinctly described as:

$$
\begin{gathered}
Y_{i j}=\gamma_{00}+\gamma_{01} W_{j}+\gamma_{10} X_{i j}+\gamma_{11} W_{j} X_{i j}+u_{0 j} \\
+u_{1 j} X_{i j}+\varepsilon_{i j}
\end{gathered}
$$

in which the achievement in employment security $Y_{i j}$ of individual $i$ nested in context $j$ is explained by the average achievement at the context level and by a vector of individual $\left(X_{i j}\right)$ and of contextual $\left(W_{j}\right)$ characteristics.

Social participation enters into the equation jointly with other meso variables that attempt to explain the latent contextual effect. The number of living children enters into the model as $X$ variable. In this case, the sign of $\gamma_{10} X_{i j}$ helps distinguish between a substitution effect (negative sign) and an income-effect (positive sign). The parameter $\gamma_{11} W_{j} X_{i j}$ describes how the fertility-labour link is altered by the contextual variable $W_{j}$.

Model Specification I first compute the intraclass coefficient: this captures the total variability in the dependent variable that is explained by the context. The latent contextual effect is more important in Mali - accounting for $33 \%$ in the variance of employment security than in Ghana, where it accounts for 17\%. In a second stage, I fit my model by introducing covariates at both levels. The aim is to reduce the unexplained effect of the context by including contextual features that are relevant. The final model is satisfactory, explaining $79 \%$ (99\%) of the variance at level 2 and $17 \%$ (36\%) of variance at level I in Mali (Ghana).

\section{How to interpret the graphical analysis}

Figure 3 shows typical results of a random slope model. Different types of participation contexts represented as separate lines, show how social participation can improve individual employment security (Bold arrows). Type of participation could change average security (increase in the intercept), e.g. through efficient lobbying of workers for their rights. This implies improved baseline features in the graph, which can be interpreted as average collective endowments or resources ( $E$ in figure 3 ). 


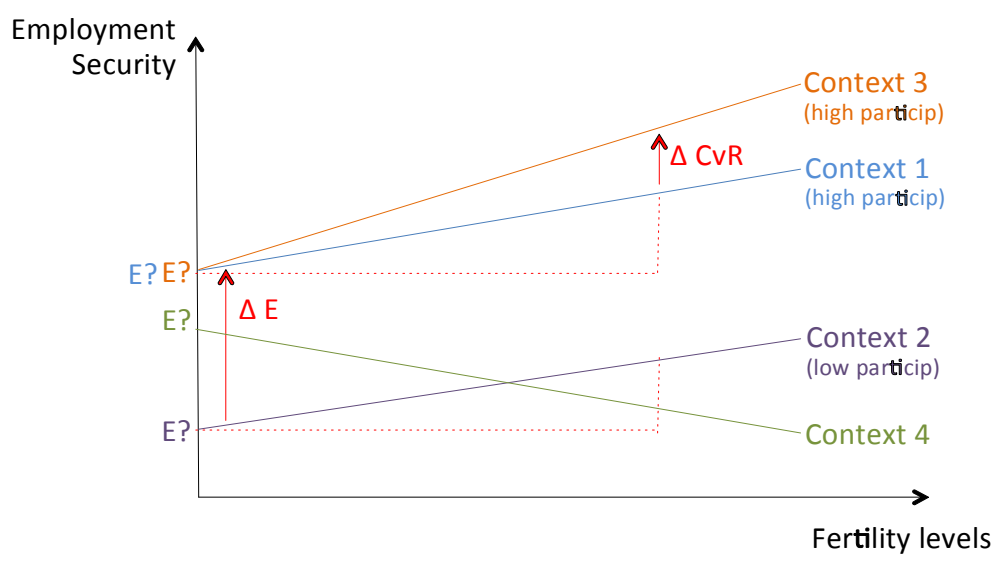

Figure 3: Random slope model: channels through which social participation context can affect employment security and the fertility-labour link. Source: elaboration by the author.

On the other hand, the social participation context might have a 'differentiating' effect on women with different fertility levels or for different subgroups of the population (e.g. older or younger women). A positive slope expresses an income effect, while negative slopes show a substitution effect (CvR in figure 3 ). These differentiating effects highlight different types and dynamics of inequalities. Structural inequalities or vulnerabilities associated to subgroups emerge as heterogeneity in intercepts: if contexts with varying intensity or type of participation all start from the same average employment security level, then the contextual variable does not play a relevant role.

The type of link between employment security and fertility level highlights the role of the participation context for the work-family balance. Context 4 in figure 3 shows cases where mothers of many children tend to be marginalized from the labour market: they enjoy a low baseline level in employment security, and it tends to decrease even more with greater numbers of children. Such a condition means that women de facto are not able to combine fertility with employment security in the context where they live.

Through the graphical analysis we are therefore testing two hypotheses:

Hypothesis (A) The participatory context can affect female employment security by providing a better baseline (higher intercepts).

Hypothesis (B) Participation is a favourable contextual characteristic for those who combine employment security and motherhood (positive slope).

\section{Results}

Levels of Employment Security (Figure 4)

Employment security patterns differ between the two countries: conditions among the youngest women (15-19) are not substantially different, but for older age groups, average values of Having $a$ Job are much higher in Ghana than in Mali. Similarly, Women in Ghana tend to Earn Regularly much more. Employment Formality increases with age in Ghana, but not in Mali, where the degree of formality is rather constant among women who declare a professional activity. 
Social Participation in Mali and Ghana:

Drivers, Characteristics and Gender Differences

Simple correlational analyses on the Afrobarometer data (2008) show that the main driving force of the composite indicator of social participation is the intensity of membership in associations and groups. This active participation does not correlate highly with membership in religious groups, but is positively associated (more than 0.45 in both countries) with the participatory position. For participatory position, it is "attending community meetings" and "joining others to raise an issue" that seem to be main drivers. In both countries, "participation in demonstrations and protest marches" is less frequent still weakly positively associated to membership in community groups but not significantly linked to membership in religious groups.

In both countries, participation patterns are not drastically different in average terms (Figure 4) and women tend to participate less than men. In Ghana, differences can mainly be found in leading positions (less female official leaders) and in the frequency of activities while, in Mali the share of women not participating at all is consistently higher. Membership is less frequent in Mali, at all urbanization levels. In Ghana, social participation tends to be higher in the countryside.

The unsatisfied desire for increased participation is somewhat stronger among men and much higher in Mali $(58 \%$ of not participating men, $43 \%$ of not participating women) compared to Ghana (27\% of not participating men, $20 \%$ of not participating women). Intermediate positions among those who are not participating (desire to participate only in some activities) are more common among women (about $21 \%$ in Mali, about $40 \%$ in Ghana) than among men (about I I\% in Mali, about $26 \%$ in Ghana).

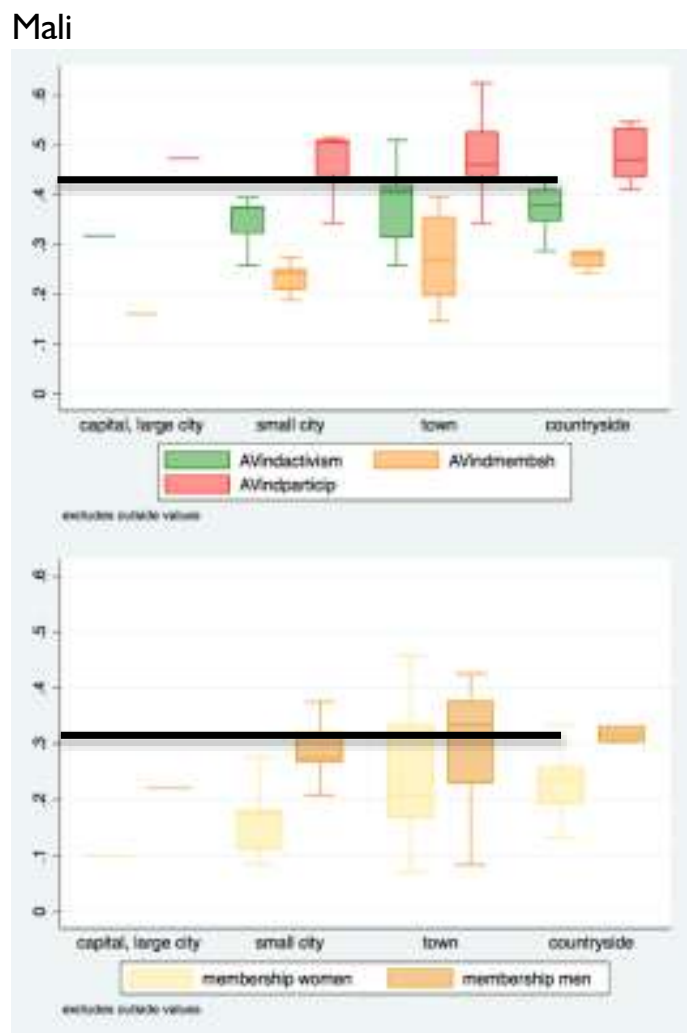



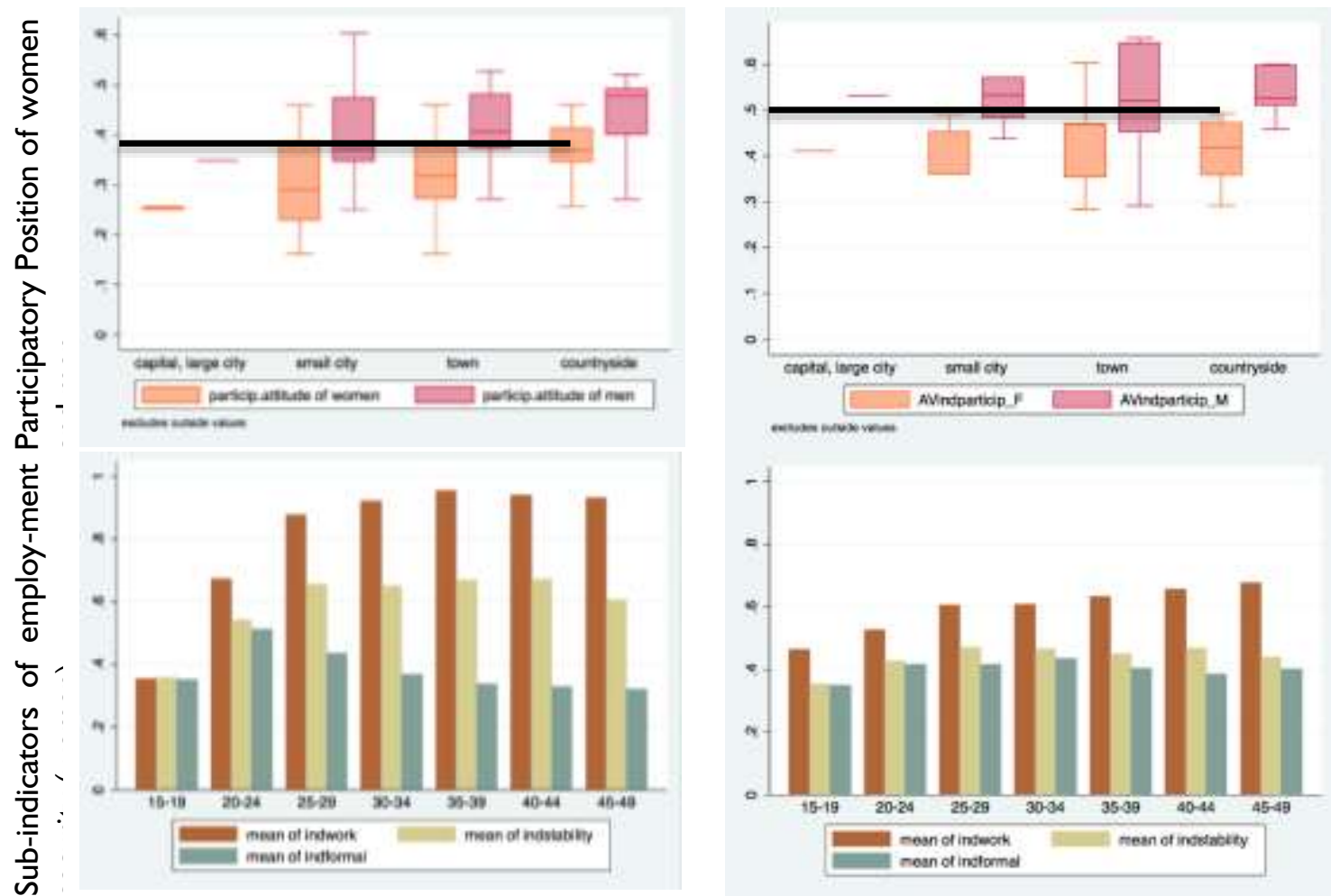

Figure 4: Employment security and participatory profile in Ghana and Mali, 2008 and 2006

Source: author's elaboration on Afrobarometer Ghana (2008) and Mali (2008); DHS Ghana (2008) and Mali (2006).

Results of the Multilevel Analysis.

\section{Factors affecting female employment security (Table I).}

The multilevel analysis has been implemented through a series of models throughout which signs and sizes of coefficients tend to be robust. The preferred model for analysis and further results is model 5 as it has the highest explicatory potential at both levels. Models differ by alternatively dropping some variables, such as age, an indicator of female empowerment, assets that provide assistance for domestic work, average wealth, healthrelevant infrastructure and occupational diversification.

In Ghana employment security is greater among older women, but does not correlate with fertility. It is higher in the agricultural sector and more so in places where the time needed to pick water is greater. On the other hand, women with higher socio-economic background (wealth index) who read the newspaper and achieved higher education also tend to have higher employment security.
Female empowerment is also correlated to greater employment security, as shown by a significant, positive coefficient of the 'decision index' in which the ability of the woman to participate in relevant decisions in the household is measured. ${ }^{6}$

Contextual features that correlate with higher individual employment security are average schooling, social participation and average wealth. Inequality at the context level (Gini wealth index) does not seem to be significant. Negative associations can be found for the share of non-working women: where fewer women work, a working woman is less likely to have a secure job.

In Mali employment security correlates positively with increasing age but negatively with higher fertility levels. The job stability of the partner, female empowerment and occupation in the agricultural sector are also positively associated to higher employment security, while living in a place where the time needed to pick water is greater appears to affect negatively their opportunity for secure 
employment. Intriguing results are that in Mali higher education is consistently associated to lower employment security and that there is no significant association with the household wealth. This may indicate that employment security, such as defined here, is not seen as a valuable option for women with greater resources.

Not many contextual features included in the common model for both countries are significant in Mali. This may reflect basic structural differences with Ghana, i.e. a context of high fertility and low participation in the labour market. The only statistically significant factor is local inequality in terms of socioeconomic standards. Greater inequality correlates with higher employment security. In previous analyses on the same data, we found higher inequality to be associated with lower fertility. There might be an indirect effect of reduced fertility on greater employment security, which is not observable, here. Social participation is weakly associated to higher employment security (coefficients are not statistically significant in Mali). In two models, individual employment security is negatively correlated with the local proportion of nonworking women.

\section{The association between social participation context, employment security and the fertility-labour link (Figure 5)}

The composite indicator and the different measures of social participation described above (Figure 2) are used here to analyse differences in social participation across the country. Each geographical unit (3I in Ghana and 25 in Mali) is considered regarding its position in the distribution of the indices and they are grouped by quartiles in Figure 5 . The rural context in the region of Tombouctou, for example, locates within the second quartile of the distribution of share of individuals participating $(B)$ and in the first quartile for what concerns the ratio between female and male participation.
Participation vs. Employment Security Baseline Positions (Intercepts in the Graphs): In order to detect whether social participation might play a role for average employment security of women, I concentrate on estimated random intercepts.

In Ghana differences in the intensity and type of social participation are not linked to diverse baseline positions for female employment achievements. This is recognizable by very similar intercepts of the different categories of social participation (see Figure 5).

In Mali, baseline positions tend to differ between the participation groups but not in a linear or monotonic way. Highest intercepts can for example be found at intermediate $\left(2^{\text {nd }}\right.$ quartile) and high ( $4^{\text {th }}$ quartile) participation shares (B) - just as at low (I ${ }^{\text {st }}$ quartile) and high ( $4^{\text {th }}$ quartile) intensity of participation as measured by the composite index ${ }^{7}$. A consistent trend is however seen with regards to the ratio between female and male participation (B): higher intercepts come with greater female participation. More gender equality in participation is thus correlated with higher average levels in female employment security. This is also found in contexts with a higher rate of unsatisfied desire for more participation. Female empowerment is likely to be the common driver of this empirical fact. Where women are able to participate socially, they are also more able to participate in the labour market.

Context participation and the fertility-labour link: The slopes in figure 5 highlight the association between social participation and the fertility-labour link.

In Ghana, women living in contexts with the lowest social participation, and with higher unsatisfied desire to participate, appear to have more difficulties to conciliate high fertility and job security (substitution effect). A substitution effect is also found when the female/male membership ratio increases: where women are also engaged in community life, they might be less able, or less willing to conciliate jobs and large families.

In Mali, it is more difficult to identify trends. The income effect is prevalent among women 
of medium-low ( $\mathrm{I}^{\text {st }}$ and $2^{\text {nd }}$ quartile) levels of participation (index B): in such contexts, women tend to be able to combine higher fertility with greater employment security (positive slope). When using the global composite participation index, an increasingly more pronounced substitution effect is associated with greater participation. Participation might be thought to play a role in changing the 'social role' of women, facilitating a transition towards lower fertility. In terms of female to male participation rate the trend is similar. A greater participation of women in terms of membership tends to be associated with a substitution effect, just as in Ghana. When measured by the participation index (B), the substitution effect is found both at the $\left.\right|^{\text {st }}$ and $4^{\text {th }}$ quartile.

Marginalization from the labour market: Figure 5 allows detection of those contexts in which women tend to be 'marginalized' from the labour market. Such a situation is identified when women in a context have consistently low levels of employment security, and when increasing fertility leads to further decreases in such security. The data analysis suggests that in Ghana this is likely in contexts in which social participation is lower and where female participation is much lower than that of men. It is also likely to happen in contexts in which the unsatisfied desire for more participation is greatest.

In Mali, trends again are less clear, but women tend to be 'marginalized' from the labour market in contexts in which overall participation is medium-low, and where female participation is lower. A difference with respect to Ghana is that marginalization seems to be more common where the expressed desire to participate more is weak. These findings again suggest that in contexts of reduced participatory habit and attitude, the 'social role' of women tends to isolate them from the labour market
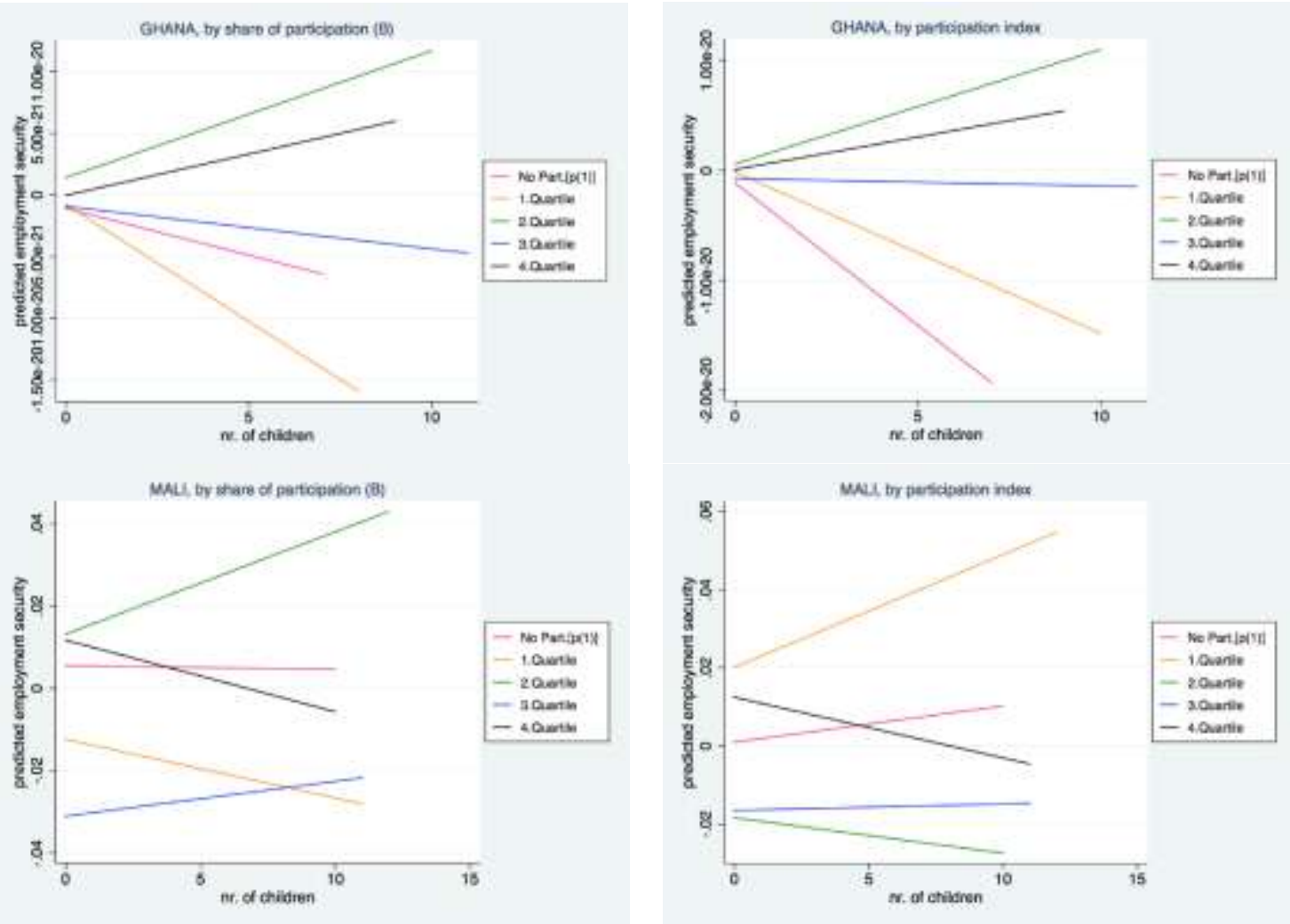

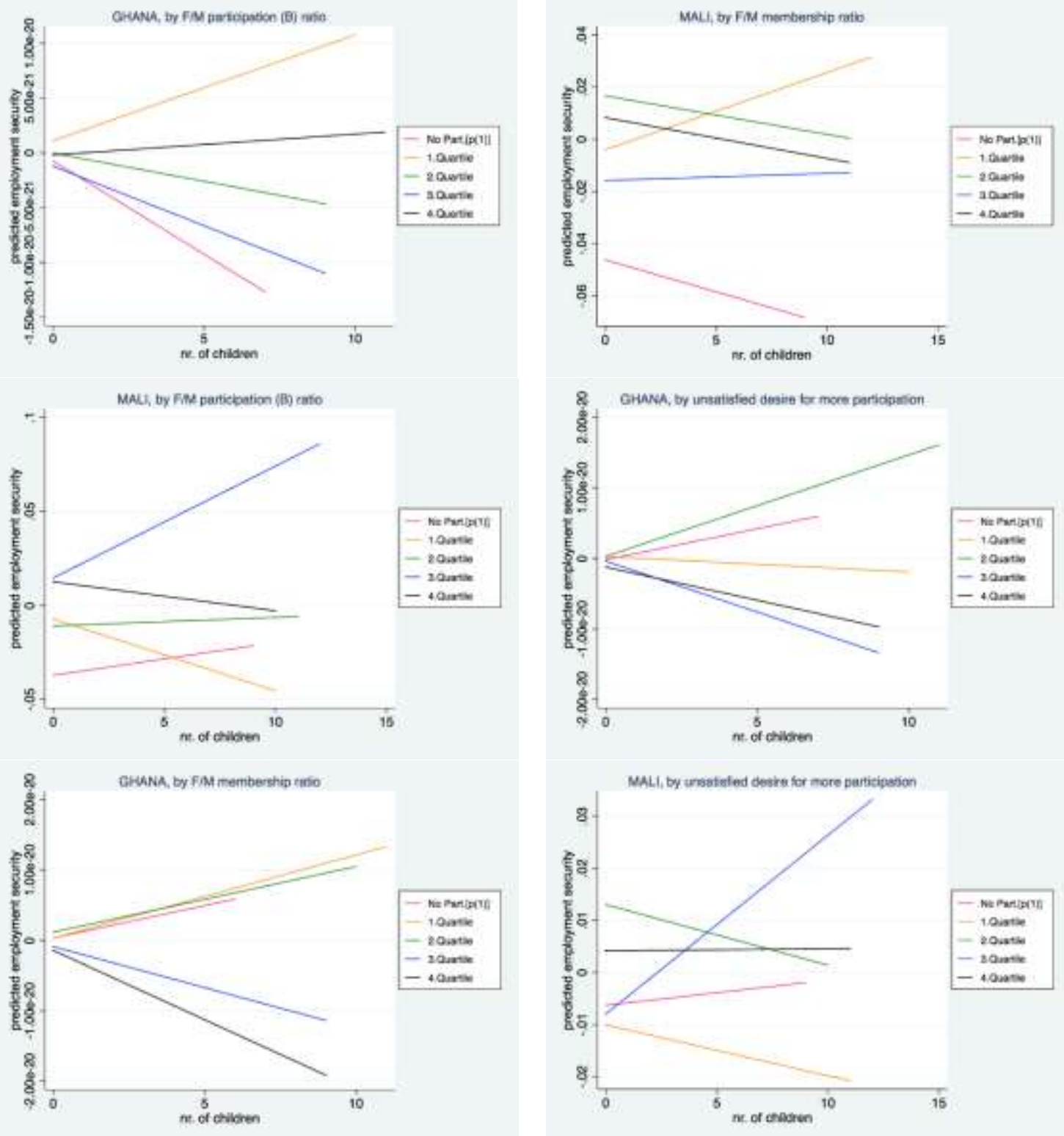

Figure 5: Random slope model, predicted levels of employment security by different social participation profiles. Baseline positions (intercepts) and trends with respect to the number of children, source: elaboration by the author ${ }^{8}$. Variables' range in Ghana/Mali:

Participation Index B [0.13:0.79][0.25:0.86];

participation of women/men [0.11:3] [0.25:2];

membership index women/men [0.53:1.75] [0.17:2.5];

unsatisfied desire for more part. [0.13:0.63] [0.17:0.83]

Sub-group analysis by age and fertility level

Sub-group analyses highlight interesting life course trends. In both countries, employment security of women appears to be significantly associated in families with 5 to 6 children. At these fertility levels also social participation is most significantly associated to the fertilitylabour link. Moreover, in both countries, social participation and fertility are not statistically related to employment security among the youngest women (I5-24 years). It is for women of age 25 to 34 that, in both countries, social 
participation is most significant, with a clear positive effect on employment security. This finding suggests that participation may be a good proxy for social cohesion which, in turn, seems to function as a collective endowment for women who need to rear many children. For older women (35-49 years) the effect remains positive and significant in Ghana but becomes insignificant in Mali.

\section{Conclusion and Discussion}

The analysis suggests that it is important to consider local levels of participation when studying employment of women and their ability to combine a large family with professional activity. The results are indicative of a positive relation between participation and employment security, especially for the subgroup of adult women between 25 and 34 years and for mothers of 5 to 6 children (moderatehigh fertility).

In general, the results of the analysis suggest that participation, fertility, labour choices and empowerment are strongly intertwined. The intensity and type of participation can therefore be considered as a collective conversion factor influencing employment security and the ability to conciliate it with a large family. Social participation seems to play a role of facilitator for child-rearing in Ghana: greater social participation is associated with an increased ability to combine large families and employment security. It seems that in contexts with greater social cohesion, the rearing of children is a duty that does not fall only on the mother but is shared by the whole community giving more freedom to the mother to commit to other activities. In Mali, the interpretation of the results depends on the 'flavour' given to a substitution effect. On one side, greater participation is likely to be associated to a change in the 'social role' of women towards greater female empowerment and reduced fertility. On the other side, when the overall share of participation is higher, women tend to suffer a disadvantage, either because their average employment security (baseline position) is low, or because higher fertility is associated to lower employment security. A crucial question remains how to interpret the role of income and substitution effects: more information on the dynamics of female empowerment seems to be necessary to properly understand when women prefer renouncing on a job to pursue motherhood and when they feel constrained in combining these two aspects of life.

The extent to which women participate similarly to men also plays a role: in Mali this is associated to higher baseline positions in employment security. Interestingly, women with many children that live in contexts where they participate similarly to men tend to converge to a situation in which employment security is lower. If these contexts can be thought of as 'more empowered' in average terms, then the choice to have many children and to renounce on a secure job might be what Malian women have 'reason to value'. A similar intuition emerges in the analysis of women that are marginalized from the labour market: in Ghana, this seems to happen in contexts where there is an unsatisfied desire for more participation, and in Mali, on the contrary, where the desire for greater participation is low. 
Unfortunately, neither the DHS data nor the Afrobarometer provide details on the motivations of participation and on the choice of the type of affiliated associations ${ }^{9}$. We do not know whether the chosen association or group has an economic relevance such as shown in the Mali youth survey (see Dieng in this volume) or any specific link to the labour market. Future data collection efforts could gather more detailed information on why people interact with others and with whom. This would allow a better understanding on why some groups remain isolated. Improved collections of nested data, possibly through time, might further allow improving our understanding of contextual influences on individual choices and conditions.
Previous analyses that we carried out in this project suggest that social participation is tightly interconnected with other factors that affect the fertility-labour link. For example, structural and cultural differences in terms of female empowerment, labour market participation and female labour market development between the two countries concur in explaining these differences. One has also to take in account the differences in average fertility levels (see the introduction to this volume). The fertility-labour link has different meanings when large families are the rule or are limited to specific subpopulations. 
African Population Studies Vol 28, No.2 June 2014

Table I: Factors associated with Employment Security. Multilevel analysis, Ghana and Mali, 2008 and 2006

\begin{tabular}{|c|c|c|c|c|c|c|c|c|c|c|c|c|c|c|c|}
\hline \multicolumn{16}{|l|}{ Ghana } \\
\hline \multirow[b]{2}{*}{ Dependent Variable: Employment Security IND } & \multicolumn{3}{|c|}{ model3 } & \multicolumn{3}{|c|}{ model4A } & \multicolumn{3}{|c|}{ model4B } & \multicolumn{3}{|c|}{ model4C } & \multicolumn{3}{|l|}{ model5 } \\
\hline & Coef. & p-val & S. & Coef. & p-val & S. & Coef. & p-val & S. & Coef. & $\mathrm{p}$-val & S. & Coef. & $\mathrm{p}$-val & S. \\
\hline Age & 0.002 & 0.034 & $* *$ & 0.002 & 0.035 & $* *$ & & & & & & & 0.002 & 0.046 & $* *$ \\
\hline Fertility & -0.004 & 0.351 & & -0.004 & 0.332 & & 0.002 & 0.501 & & 0.002 & 0.540 & & -0.003 & 0.488 & \\
\hline partner_jobstability & 0.000 & 0.927 & & 0.001 & 0.913 & & 0.000 & 0.968 & & 0.000 & 0.980 & & 0.000 & 0.956 & \\
\hline years of education & 0.001 & 0.535 & & 0.001 & 0.539 & & 0.001 & 0.364 & & 0.001 & 0.372 & & 0.003 & 0.104 & $*$ \\
\hline agricultural sector & 0.034 & 0.034 & $* *$ & 0.035 & 0.031 & $* *$ & 0.035 & 0.030 & $* *$ & 0.035 & 0.029 & $* *$ & 0.031 & 0.054 & $* *$ \\
\hline wealth index & 0.000 & 0.034 & $* *$ & 0.000 & 0.053 & $* *$ & 0.000 & 0.058 & $*$ & 0.000 & 0.075 & $*$ & 0.000 & 0.093 & $*$ \\
\hline stable partner.notliving.tog & -0.004 & 0.791 & & -0.003 & 0.836 & & -0.003 & 0.860 & & -0.003 & 0.877 & & -0.007 & 0.697 & \\
\hline FemEmpower_HHdecision & 0.003 & 0.000 & $* * *$ & 0.003 & 0.000 & $* * *$ & 0.003 & 0.000 & $* * *$ & 0.003 & 0.000 & $* * *$ & 0.003 & 0.000 & $* * *$ \\
\hline FemEmpower_sexdecision & 0.000 & 0.253 & & & & & 0.000 & 0.250 & & & & & 0.000 & 0.341 & \\
\hline inhibited own health & 0.010 & 0.680 & & 0.005 & 0.850 & & 0.002 & 0.928 & & -0.002 & 0.940 & & 0.007 & 0.789 & \\
\hline time to pick water & 0.001 & 0.016 & $* *$ & 0.001 & 0.014 & $* * *$ & 0.001 & 0.015 & $* *$ & 0.001 & 0.014 & $* * *$ & 0.001 & 0.024 & $* *$ \\
\hline househelp_assets & 0.000 & 0.270 & & & & & 0.000 & 0.351 & & & & & 0.000 & 0.337 & \\
\hline reads newspaper & 0.001 & 0.001 & $* * *$ & 0.001 & 0.001 & $* * *$ & 0.001 & 0.000 & $* * *$ & 0.001 & 0.000 & $* * *$ & 0.001 & 0.010 & $* * *$ \\
\hline ctx_meanschooling & 0.055 & 0.000 & $* * *$ & 0.053 & 0.000 & $* * *$ & 0.016 & 0.145 & & 0.016 & 0.146 & $* * *$ & 0.055 & 0.000 & $* * *$ \\
\hline ctx_social participation & 0.363 & 0.026 & $* *$ & 0.393 & 0.008 & $* * *$ & 0.437 & 0.009 & $* * *$ & 0.468 & 0.006 & $* * *$ & 0.397 & 0.003 & $* * *$ \\
\hline ctx_wealthindex & 0.000 & 0.000 & $* * *$ & 0.000 & 0.000 & $* * *$ & & & & & & & -0.066 & 0.000 & $* * *$ \\
\hline ctx_infrastructure & 0.001 & 0.751 & & & & & & & & & & & & & \\
\hline share nonworking women & -0.267 & 0.015 & $* *$ & -0.287 & 0.011 & $* * *$ & -0.427 & 0.000 & $* * *$ & -0.438 & 0.000 & $* * *$ & -0.335 & 0.001 & $* * *$ \\
\hline share female_headed $\mathrm{HHs}$ & 0.002 & 0.025 & $* *$ & 0.002 & 0.019 & $* *$ & 0.002 & 0.001 & $* * *$ & 0.002 & 0.001 & $* * *$ & 0.002 & 0.003 & $* * *$ \\
\hline ctx_med. FemEmpower & -0.200 & 0.139 & & -0.204 & 0.145 & & -0.088 & 0.540 & & -0.085 & 0.559 & & -0.160 & 0.221 & \\
\hline ctx_elf & -0.018 & 0.686 & & -0.007 & 0.880 & & -0.002 & 0.975 & & 0.007 & 0.905 & & -0.013 & 0.757 & \\
\hline ctx_gini (WI) & -0.092 & 0.760 & & -0.182 & 0.533 & & -0.155 & 0.618 & & -0.177 & 0.576 & & 0.138 & 0.607 & \\
\hline ctx_occupational_diversific & -0.040 & 0.707 & & -0.026 & 0.809 & & & & & & & & -0.048 & 0.625 & \\
\hline _constant & 0.003 & 0.987 & & 0.026 & 0.842 & & 0.218 & 0.088 & $*$ & 0.211 & 0.099 & * & 0.071 & 0.559 & \\
\hline $\mathrm{R}^{\wedge} 2$ level 1 & 0.359 & & & 0.359 & & & 0.359 & & & 0.359 & & & 0.360 & & \\
\hline $\mathrm{R}^{\wedge} 2$ level 2 & 0.859 & & & 0.780 & & & 0.576 & & & 0.556 & & & 1.000 & & \\
\hline $\mathrm{R}^{\wedge} 2$ (proxy) & 0.443 & & & 0.430 & & & 0.395 & & & 0.392 & & & 0.468 & & \\
\hline
\end{tabular}


African Population Studies Vol 28, No.2 Julne 2014

\begin{tabular}{|c|c|c|c|c|c|c|c|c|c|c|c|c|c|c|c|}
\hline \multicolumn{16}{|l|}{ Mali } \\
\hline \multirow[b]{2}{*}{ Dependent Variable: Employment Security IND } & \multicolumn{3}{|c|}{ model 3} & \multicolumn{3}{|c|}{ model $4 \mathrm{~A}$} & \multicolumn{3}{|c|}{ model4B } & \multicolumn{3}{|c|}{ model $4 \mathrm{C}$} & \multicolumn{3}{|c|}{ model5 } \\
\hline & Coef. & p-val & S. & Coef. & $p$-val & S. & Coef. & $p$-val & S. & Coef. & $\mathrm{p}$-val & S. & Coef. & $\mathrm{p}$-val & S. \\
\hline Age & 0.001 & 0.256 & & 0.001 & 0.056 & * & & & & & & & 0.001 & 0.044 & ** \\
\hline Fertility & -0.004 & 0.053 & ** & -0.005 & 0.027 & ** & -0.002 & 0.208 & & -0.002 & 0.210 & & -0.005 & 0.032 & ** \\
\hline partner_jobstability & 0.009 & 0.002 & $* * *$ & 0.008 & 0.004 & $* * *$ & 0.010 & 0.000 & $* * *$ & 0.010 & 0.001 & $* * *$ & 0.008 & 0.023 & ** \\
\hline years of education & -0.005 & 0.004 & $* * *$ & -0.004 & 0.010 & $* * *$ & -0.004 & 0.010 & $* * *$ & -0.004 & 0.009 & $* * *$ & -0.004 & 0.010 & $* * *$ \\
\hline agricultural sector & 0.278 & 0.000 & $* * *$ & 0.279 & 0.000 & $* * *$ & 0.280 & 0.000 & $* * *$ & 0.279 & 0.000 & $* * *$ & 0.279 & 0.000 & $* * *$ \\
\hline wealth index & 0.000 & 0.719 & & 0.000 & 0.159 & & 0.000 & 0.747 & & 0.000 & 0.090 & * & 0.000 & 0.710 & \\
\hline stable partner.notliving.tog & -0.038 & 0.021 & ** & -0.042 & 0.010 & $* * *$ & -0.038 & 0.019 & ** & -0.039 & 0.015 & ** & -0.043 & 0.009 & *** \\
\hline FemEmpower_HHdecision & 0.005 & 0.000 & $* * *$ & 0.005 & 0.000 & $* * *$ & 0.005 & 0.000 & $* * *$ & 0.005 & 0.000 & $* * *$ & 0.005 & 0.000 & $* * *$ \\
\hline FemEmpower_sexdecision & 0.000 & 0.254 & & & & & 0.000 & 0.106 & & & & & 0.000 & 0.102 & * \\
\hline inhibited own health & 0.027 & 0.003 & $* * *$ & 0.027 & 0.003 & $* * *$ & 0.027 & 0.003 & $* * *$ & 0.027 & 0.003 & $* * *$ & 0.027 & 0.003 & $* * *$ \\
\hline time to pick water & -0.001 & 0.000 & $* * *$ & -0.001 & 0.000 & $* * *$ & -0.001 & 0.000 & $* * *$ & -0.001 & 0.000 & $* * *$ & -0.001 & 0.000 & $* * *$ \\
\hline househelp_assets & 0.000 & 0.226 & & & & & 0.000 & 0.149 & & & & & 0.000 & 0.158 & \\
\hline reads newspaper & 0.001 & 0.282 & & 0.000 & 0.479 & & 0.000 & 0.441 & & 0.000 & 0.457 & & 0.000 & 0.484 & \\
\hline ctx_meanschooling & -0.018 & 0.247 & & -0.015 & 0.290 & & 0.003 & 0.700 & & 0.003 & 0.728 & & -0.003 & 0.807 & \\
\hline ctx_social participation & 0.295 & 0.085 & * & 0.230 & 0.116 & & 0.215 & 0.144 & & 0.195 & 0.185 & & 0.232 & 0.126 & \\
\hline ctx_wealthindex & 0.000 & 0.232 & & 0.000 & 0.144 & & & & & & & & 0.011 & 0.432 & \\
\hline ctx_infrastructure & -0.001 & 0.901 & & & & & & & & & & & & & \\
\hline share nonworking women & -0.136 & 0.556 & & -0.210 & 0.346 & & -0.252 & 0.000 & $* * *$ & -0.245 & 0.001 & $* * *$ & -0.225 & 0.329 & \\
\hline share female_headed $\mathrm{HHs}$ & 0.000 & 0.922 & & 0.001 & 0.657 & & 0.002 & 0.348 & & 0.002 & 0.335 & & 0.001 & 0.642 & \\
\hline ctx_med. FemEmpower & -0.074 & 0.788 & & -0.193 & 0.463 & & -0.089 & 0.713 & & -0.093 & 0.705 & & -0.129 & 0.627 & \\
\hline ctx_elf & 0.256 & 0.009 & $* * *$ & 0.224 & 0.012 & $* * *$ & 0.179 & 0.012 & $* * *$ & 0.189 & 0.008 & $* * *$ & 0.197 & 0.033 & $* *$ \\
\hline ctx_gini (WI) & -0.170 & 0.380 & & -0.052 & 0.773 & & -0.141 & 0.414 & & -0.119 & 0.490 & & -0.130 & 0.470 & \\
\hline ctx_occupational_diversific & -0.115 & 0.716 & & 0.009 & 0.978 & & 0.160 & 0.131 & & & & & -0.037 & 0.906 & \\
\hline constant & 0.163 & 0.205 & & 0.115 & 0.363 & & & & & 0.148 & 0.162 & & 0.140 & 0.302 & \\
\hline$R^{\wedge} 2$ level 1 & 0.169 & & & 0.172 & & & 0.172 & & & 0.171 & & & 0.172 & & \\
\hline $\mathrm{R}^{\wedge} 2$ level 2 & 0.801 & & & 0.800 & & & 0.789 & & & 0.787 & & & 0.787 & & \\
\hline $\mathrm{R}^{\wedge} 2$ (proxy) & 0.379 & & & 0.380 & & & 0.377 & & & 0.376 & & & 0.376 & & \\
\hline
\end{tabular}

Source: author's elaboration on DHS Ghana (2008) and DHS Mali (2006), matched with Afrobarometer Ghana (2008) and Mali (2008). R² are proxies measuring \% of explained variance (for its computation,see Snijders and Bosker, 1999, Albright and Marinova, 2010, Rabe-Hesketh and Skrondal, 2012) 


\section{References}

Amin, S. 1997. "The Poverty-Purday Trap in Rural Bangladesh: Implications for Women's Roles in the Family" Development and Change Vol. 28, p 213-233.

Banerjee, A. V. 1992. "A Simple Model of Herd Behavior" The Quarterly Journal of Economics, Vol. 107, No. 3, p. 797 - 817.

Bardhan, P. and Udry, C. (eds.) 1999. Development Microeconomics. UK: Oxford University Press.

Bikhchandani et al., 1992. "A Theory of Fads, Fashion, Custom, and Cultural Change as Informational Cascades" Journal of Political Economy, Vol. 100, No. 5, p. 992 - 1026.

Bongaarts and Cotts Watkins, 1996. "Social Interactions and Contemporary Fertility Transitions" Population and Development Review, Vol. 22, No. 4, p. 639 -682.

Chiappero-Martinetti, E. 1994. "A new approach to evaluation of well-being and poverty by fuzzy set theory" Giornale degli economisti e annali di economia 7-9: 367388

Chiappero-Martinetti, E. and von Jacobi, N. 20II. "Light and Shade of Multidimensional Indexes: How Methodological Choices Impact on Empirical Results" in Quality of life in Italy: Research and Reflections. Social Indicators Research Series 48: 69-103. Springer Science + Business Media

Chiappero-Martinetti, E. and Salardi, P. 2008. "Well-being process and conversion factors: an estimation" Working Paper Series 3, Human Development, Capability and Poverty International Research Centre

Cicognani, E. and Pirini, C. and Keyes, C and Joshanloo, M. and Rostami, R. and Nosratabadi, M. 2008. "Social Participation, Sense of Community and Social Well Being: A Study on American, Italian and Iranian University Students" Social Indicator Research 89:97-I 12

Esau, M.V. 2008. "Contextualizing Social Capital, Citizen Participation and Poverty through an Examination of the Ward Committee System in Bonteheuwel in the Western Cape, South Africa" Journal of Developing Societies 24, (3): 355-380
Gatti, F. 20II. Empowerment e salute riproduttiva: un caso studio. Master thesis, Università degli Studi di Pavia.

v. Jacobi, N. 2014. Meso-factors of development: the role of the context for human development achievements. PhD thesis. IUSS Pavia.

Kandori, M. 1992. "Social Norms and Community Enforcement" The Review of Economic Studies, Vol. 59, No. I, p. 63 - 80.

Kuklys, W. 2005. Amartya Sen's Capability Approach: Theoretical Insights and Empirical Applications. Berlin: Springer.

Longshore Smith, M. and Seward, C. 2009. "The Relational Ontology of Amartya Sen's Capability Approach: Incorporating Social and Individual Causes" Journal of Human Development and Capabilities 10(2): 213235

Luke, D.A. 2004. Multilevel Modelling. Sage university paper series: Quantitative Applications in the Social Sciences. Thousand Oaks, CA: Sage Publications.

Manski, C. 1993. "Identification of Endogenous Social Effects: The Reflection Problem" The Review of Economic Studies, Vol. 60, No. 3, p. 53 I -542 .

Munshi, K. and Myaux, J. 2006. "Social norms and the fertility transition" Journal of Development Economics 80: I - 38.

Nardo, M., Saisana, M., Saltelli, A., Tarantola, S., Hoffman, A., \& Giovannini, E. 2005. Handbook on constructing composite indicators: methodology and user guide. No. 2005/3. OECD publishing.

Platt, L. 2006. "Social Participation: How does it vary with illness, caring and ethnic group?", ISER Working Paper 2006-18. Colchester: University of Essex.

Postlewaite, A. 1998. "Social Status, Norms and Economic Performances: The social basis of interdependent preferences" European Economic Review 42, p. 779 - 800.

Putnam, R. 1993. Making Democracy Work. Princeton, NJ: Princeton University Press.

Putnam, R. and Goss, K.A. 2002. Democracies in Flux: The Evolution of Social Capital in Contemporary Society. New York: Oxford University Press. 
Robeyns, I. 2005. "The Capability Approach: a theoretical survey" Journal of Human Development 6(I): 93-II7

Sen, A. 1985. Commodities and Capabilities. Prof. Dr. P. Hennipman lectures in economics. Amsterdam: North-Holland.

Sen, A. 1992. Inequality revisited. Clarendon Press.

Sen, A. 1999. Development as Freedom. Oxford, UK: Oxford University Press.

Sen, A. 2009. The idea of justice. London, UK: Allen Lane. ability to refuse sex with the own partner (see Gatti, 2011).

${ }^{7}$ The simple correlation coefficient between the participation index and the intercept is significant and negative (-0.302).

${ }^{8}$ No part $[p(1)]$ stands for 'no participation' or the first percentile in the distribution of the variable. In the case of 'unsatisfied desire for more participation' this should be interpreted as absence of unsatisfied desire.

${ }^{9}$ I am thankful to Michael Grimm for this comment.

1 The Afrobarometer is an "independent, nonpartisan research project that measures the social, political, and economic atmosphere in Africa" (afrobarometer.org).

${ }^{2}$ Of course the individual can actively change its surrounding, but I assume that contextual characteristics are not modifiable by the single individual in the short term.

${ }^{3}$ For Ghana the two datasets are collected during the same year, in Mali there is a gap of 2 years between the Afrobarometer and the DHS dataset. The rather strong assumption that we need to make is that contextual characteristics change at slower pace and that 2008 values are still good proxies for the 2006 values.

${ }^{4}$ Being paid in-kind is however preferable in times of macroeconomic instability. It can also imply time saving, especially where the provision of food is a duty of the woman.

${ }^{5}$ The two sub-dimensions correlate at about 0.4, using equal weights. Within sub-dimensions, indicators correlate at about 0.25 for membership and at 0.65 for attitudes towards attending a community meeting and towards joining others to raise an issue, and at about 0.25 for attitude towards attending a demonstration and joining others and 0.20 for attending demonstrations and attending a community meeting.

${ }^{6}$ The two empowerment indexes measure the ability to participate in household decisions and the 